\title{
Glutamine supplementation improves intestinal barrier function in a weaned piglet model of Escherichia coli infection
}

\author{
Julia B. Ewaschuk ${ }^{1}$, Gordon K. Murdoch ${ }^{2}$, Ian R. Johnson ${ }^{1}$, Karen L. Madsen ${ }^{3}$ and Catherine J. Field ${ }^{1 *}$ \\ ${ }^{1}$ Department of Agricultural, Food and Nutritional Science, University of Alberta, 4-126A HRIF East, Edmonton, AB, \\ Canada T6G $2 P 5$ \\ ${ }^{2}$ Department of Animal and Veterinary Science, University of Idabo, Moscow, ID, USA \\ ${ }^{3}$ Division of Gastroenterology, University of Alberta, Edmonton, AB, Canada, T6G 2N8
}

(Received 15 September 2010 - Revised 5 January 2011 - Accepted 26 January 2011 - First published online 18 May 2011)

\section{Abstract}

The weaning period is associated with an increased prevalence of gastrointestinal infection in many species. Glutamine (Gln) has been shown to improve intestinal barrier function and immune function in both in vivo and in vitro models. The objective of the present study was to determine the effect of dietary Gln supplementation on intestinal barrier function and intestinal cytokines in a model of Escherichia coli infection. We randomised 21-d-old piglets ( $n$ 20) to nutritionally complete isonitrogenous diets with or without Gln $(4.4 \%, \mathrm{w} / \mathrm{w})$ for 2 weeks. Intestinal loops were isolated from anaesthetised pigs and inoculated with either saline or one of the two E. coli (K88AC or K88 wild-type)-containing solutions. Intestinal tissue was studied for permeability, cytokine expression, fluid secretion and tight-junction protein expression. Animals receiving Gln supplementation had decreased potential difference (PD) and short-circuit current $\left(I_{\mathrm{SC}}\right)$ in $E$. coli-inoculated intestinal loops (PD $0.628(\mathrm{SEM} 0.151) \mathrm{mV} ; I_{\mathrm{SC}} 13.0(\mathrm{SEM} 3.07) \mu \mathrm{A} / \mathrm{cm}^{2}$ ) compared with control-fed animals (PD 1.36 (SEM 0.227) $\left.\mathrm{mV} ; I_{\mathrm{sc}} 22.4(\operatorname{sem} 2 \cdot 24) \mu \mathrm{A} / \mathrm{cm}^{2}\right)$. Intestinal tissue from control, but not from Gln-supplemented, animals responded to E. coli with a significant increase in mucosal cytokine mRNA (IL-1 $\beta$, IL-6, transforming growth factor- $\beta$ and IL-10). Tight-junction protein expression (claudin-1 and occludin) was reduced with exposure to E. coli in control-fed animals and was not influenced in Glnsupplemented piglets. Gln supplementation may be useful in reducing the severity of weaning-related gastrointestinal infections, by reducing the mucosal cytokine response and altering intestinal barrier function.

\section{Key words: Wearing: Immunity: Amino acids: Gastroenteritis}

Diarrhoeal disease is the second leading cause of mortality in children, killing approximately 1.5 million children worldwide, annually ${ }^{(1)}$. Weaning is a particularly vulnerable period, as the removal of maternal immune components coincides with the increased exposure to pathogens. Escherichia coli is a common causative agent of diarrhoea in infants and young children; numerous $E$. coli virotypes including enterotoxigenic E. coli (ETEC), enterohaemorrhagic, enteroinvasive and enteropathogenic $E$. coli exist $^{(2)}$. ETEC induces diarrhoea via the expression of a choleragen-like enterotoxin that adheres to intestinal epithelial cells and induces oversecretion of electrolytes into the intestinal lumen. The piglet has been used extensively as a model for infant $E$. coli infection ${ }^{(3)}$.

A recent study has indicated that weaning suppressed adaptive immunity immediately after weaning and subsequently for about a week ${ }^{(4)}$. In contrast, variables of the innate immune system seem to be stimulated immediately after weaning ${ }^{(4)}$. The post-weaning period involves significant changes in the composition of immune cells in the blood and intestine ${ }^{(5-8)}$. At weaning, there is a change in the number and proportion of T-cells in the blood, which is associated with a reduced ability to respond to various challenges ${ }^{(5,9,10)}$. Many antigens encountered by the immune system gain access to the body through mucosal surfaces such as the intestine and respiratory tract. Gut-associated lymphoid tissue is the largest immune organ of the body and is responsible for handling large quantities of potentially harmful antigens (reviewed in Forchielli \& Walker $^{(11)}$ ). Although gut-associated lymphoid tissue is an important immune tissue and is the first and most significant contact the immune system has with dietary antigens, few studies have examined the effect of incorporating specific nutrients into the weaning diet on the function of this tissue.

Experimental studies have shown that feeding glutamine (Gln) to infants ${ }^{(12)}$ and young animals ${ }^{(13,14)}$ reduces the incidence of infections and infectious morbidity. These effects have primarily been attributed to the effect of Gln on the health of

Abbreviations: $C_{\mathrm{t}}$, cycle threshold; CTL, control; ETEC, enterotoxigenic Escherichia coli; FI, feed intake; $G$, conductance; Gln, glutamine; $I_{\mathrm{sc}}$, short-circuit current; PD, potential difference; WT, wild-type; TBST, $10 \mathrm{mm-Tris-HCl,} \mathrm{pH} \mathrm{7·4,} 150 \mathrm{mm-NaCl}$, Tween-20. 
the intestinal epithelial cell ${ }^{(15)}$. We have previously demonstrated that Gln modifies immune cells in the mesenteric lymph nodes of newly weaned piglets by supporting a Th1-type cytokine response after T-cell stimulation ${ }^{(6)}$. Gln has also been shown to stimulate intestinal epithelial cell proliferation $^{(16)}$ and reduce apoptosis ${ }^{(17)}$. Gln is also an energy substrate for lymphocytes ${ }^{(18)}$ and macrophages ${ }^{(19)}$, is important for the optimal function of $\mathrm{T}$ - and $\mathrm{B}$-cells (reviewed in Newsholme ${ }^{(20)}$ ) and is required for neutrophil bactericidal function ${ }^{(21)}$. Gln increases intestinal expression of genes related to growth and antioxidant function, and preserves epithelial barrier function in the distal ileum of 21-d-old piglets during infection ${ }^{(22,23)}$. These observations have lent support for the concept that this amino acid may become transiently essential during periods of immune stress (reviewed in Field et al. ${ }^{(24)}$ ), notably, the weaning period. When provided orally to rodents, Gln preserved intestinal metabolism, structure and function by accelerating healing of the gut mucosa in irradiated animals through increased mitosis in the proliferative zone of the villous crypts ${ }^{(25)}$. Similarly, Gln supplementation has been shown to prevent villous atrophy in early-weaned piglets ${ }^{(26)}$.

Despite the important roles attributed to Gln in clinical nutrition $^{(27)}$, supplementation during the vulnerable weaning period has received little attention. The objective of the present study was to determine the ability of dietary supplementation with $\operatorname{Gln}(4.4 \%, \mathrm{w} / \mathrm{w})$ to improve immune and gastrointestinal function and defence against an ETEC challenge in the early post-weaning period in a piglet model. As the development of a reproducible orally induced model of ETEC infection in the piglet has proved problematic ${ }^{(3,28)}$, an in vivo closed intestinal loop model of ETEC infection was used to produce the early signs of ETEC infection.

\section{Methods}

\section{Animals and diets}

The study was reviewed and approved by the Faculty of Agriculture, Forestry and Home Economics Animal Policy and Welfare Committee, and was conducted in accordance with the Canadian Council on Animal Care guidelines. A total of four litters (ten piglets per litter) of Dutch Landrace (Genex Swine Group, Heartland Livestock Services, Regina, SK, Canada) piglets were obtained at weaning (21d) from the University of Alberta Swine Research and Technology Centre (Edmonton, AB, Canada), and were housed individually in metabolism crates, each fitted with water nipples and creep feeders. Upon receipt, piglets in each litter were randomly assigned to one of the two diet treatments: (1) basal diet with a control mixture of amino acid supplement (CTL); (2) basal diet with Gln supplement (Gln) (Table 1). These diets were formulated to meet $110 \%$ of the requirements for piglets weighing $5-10 \mathrm{~kg}$ as specified by the National Research Council of Canada. The supplement portion of the Gln diet $(60 \mathrm{~g} / \mathrm{kg})$ consisted of $43.8 \mathrm{~g} \mathrm{Gln}$, and the CTL diet consisted of an isomolar, isonitrogenous mixture of amino acids (alanine, glycine and serine), which have limited or no metabolic
Table 1. Nutrient composition of the weaning diets

\begin{tabular}{lcc}
\hline & \multicolumn{2}{c}{ Diet $(\mathrm{g} / \mathrm{kg})$} \\
\cline { 2 - 3 } Ingredients & CTL diet & GIn diet \\
\hline Wheat & 382 & 382 \\
Soyabean meal & 232 & 232 \\
Casein & 232 & 232 \\
Tallow & 38.8 & 38.8 \\
Safflower oil & 21.5 & 21.5 \\
Linseed oil & 4.7 & 4.7 \\
Limestone & 6.0 & 6.0 \\
Dicalcium phosphate & 18.9 & 18.9 \\
Salt & 2.0 & 2.0 \\
Swine vitamin/mineral premix & 0.75 & 0.75 \\
Swine trace mineral 3† & 1.00 & 1.00 \\
Vitamin $B_{12}$ & $1.67 \times 10^{-5}$ & $1.67 \times 10^{-5}$ \\
Ser & 21.0 & 0 \\
Ala & 17.8 & 0 \\
Gly & $15 \cdot 0$ & 0 \\
Sucrose & 6.2 & 16.2 \\
Gln & 0 & $43.8 \mathrm{~g}$ \\
\hline
\end{tabular}

CTL, control; Gln, glutamine.

${ }^{*}$ Vitamin premix contained (\%, w/w): protein, 3.8912\%; fat, 0.99\%; moisture $2.701 \%$; digestible energy, $359.8 \mathrm{~kJ} / \mathrm{kg}$; metabolisable energy, $343.1 \mathrm{~kJ} / \mathrm{kg}$; Ca, $25.7937 \%$; P, 0.225\%; available P, 0.0765\%; Mg, 0.1282\%; Na, 0.0328\%; $\mathrm{Fe}, 642.2313 \mathrm{mg} / \mathrm{kg}$; vitamin $\mathrm{A}, 7000014.2 \mathrm{IU}(100004.3 \mu \mathrm{g}) / \mathrm{kg}$; vitamin $D_{3}$, $700014.2 \mathrm{IU}(17500.4 \mu \mathrm{g}) / \mathrm{kg}$; vitamin E, $20000.0117 \mathrm{IU}(181818288163 \mu \mathrm{g}) / \mathrm{kg}$; vitamin K, $1500.0179 \mathrm{mg} / \mathrm{kg}$; biotin, $40.0001 \mathrm{mg} / \mathrm{kg}$; folic acid, $399.9008 \mathrm{mg} / \mathrm{kg}$; niacin, $20000.0117 \mathrm{mg} / \mathrm{kg}$; pantothenic acid, $7499.9741 \mathrm{mg} / \mathrm{kg}$; pyridoxine $533.9845 \mathrm{mg} / \mathrm{kg}$; riboflavin, $3000.0051 \mathrm{mg} / \mathrm{kg}$; thiamin, $580.5812 \mathrm{mg} / \mathrm{kg}$; vitamin $B_{12}$ $10 \mathrm{mg} / \mathrm{kg}$.

† Trace mineral premix contained (\%, w/w): fat, $0.99 \%$; moisture, $0.001 \%$; digestible energy, $359.8 \mathrm{~kJ} / \mathrm{kg}$; metabolisable energy, $343.1 \mathrm{~kJ} / \mathrm{kg}$; Ca, $15.1874 \%$; $\mathrm{Mg}$, $0.0729 \% ; \mathrm{Na}, 0.0283 \% ; \mathrm{S}, 4.756 \%$; Co, $351 \mathrm{mg} / \mathrm{kg} ; \mathrm{Cu}, 5000 \mathrm{mg} / \mathrm{kg} ; \mathrm{I}$, $749.3 \mathrm{mg} / \mathrm{kg} ; \mathrm{Fe}, 75365.1328 \mathrm{mg} / \mathrm{kg} ; \mathrm{Mn}, 25020 \mathrm{mg} / \mathrm{kg} ; \mathrm{Se}, 150 \mathrm{mg} / \mathrm{kg} ; \mathrm{Zn}$, $75024 \mathrm{mg} / \mathrm{kg}$; choline, $100.001 \mathrm{~g} / \mathrm{kg}$.

interaction with Gln and are not known to limit the growth or immune function in piglets of this age ${ }^{(29)}$. Gln supplementation level was designed to be consistent with an approximate amount (on a diet proportion) that has been added in adult human clinical studies that found beneficial effects on immune function and infection rates ${ }^{(30,31)}$. The variable portion of the diet was isonitrogenous and was made isoenergetic by balancing the supplement with sucrose. Piglets were fed the test diets for $14 \mathrm{~d}$ from weaning. Body weight and feed intake (FI) were recorded daily during the feeding trial.

\section{In situ surgical procedure}

At approximately $35 \mathrm{~d}$ of age, animals underwent an in situ closed intestinal loop ETEC infection procedure. A single blood sample was taken from each piglet before receiving anaesthesia for isolation of peripheral blood mononuclear cells. Piglets received intramuscular injections of Torbugesic $(0 \cdot 2 \mathrm{mg} / \mathrm{kg})$, Ketamine (11 mg/kg), Rompun $(2 \cdot 2 \mathrm{mg} / \mathrm{kg})$ and Robinul $(0.01 \mathrm{mg} / \mathrm{kg})$. Anaesthesia was maintained with $1 \cdot 0-1 \cdot 5 \%(\mathrm{v} / \mathrm{v})$ halothane delivered with oxygen (3litres/ min). The abdominal wall was opened by a midline incision, and the ileum was exteriorised and gently flushed with PBS to remove the intestinal contents. Intestinal loops (each $10 \mathrm{~cm}$ in length and $50 \mathrm{~cm}$ apart) were ligated with braided umbilical tape (Baxter International, Inc., Deerfield, IL, USA). The first intestinal loop was located $15 \mathrm{~cm}$ from the ligament of 
Treitz. Each loop was injected with either an ETEC suspension (K88AC or K88 wild-type (WT), approximately $1 \times 10^{9}$ colonyforming units/ml, described later) or PBS (negative control). Following an incubation period of $4 \mathrm{~h}$, euthanasia was induced by cardiac injection of pentobarbital (Euthanyl; $2 \mathrm{ml} / 4.5 \mathrm{~kg}$ body weight), and the gut sections were removed and immersed in ice-cold PBS. The amount of fluid inoculated into each loop was recorded, and the volume recovered from each loop was measured at the end of the experiment. Mucosal scrapings from each segment were snap-frozen in liquid $\mathrm{N}_{2}$ and stored at $-80^{\circ} \mathrm{C}$. Mesenteric lymph nodes were excised adjacent to the distal ileum $(10-20 \mathrm{~cm}$ before the ileocaecal junction), immersed in ice-cold PBS and stored on ice until processing.

\section{Bacterial preparation}

E. coli cultures were prepared fresh from frozen stock immediately before each surgery. We chose two representative swine ETEC strains: one well-characterised strain known to express the K88AC fimbrial antigen and one K88 + WT field isolate. To ensure that we included a strain that was infective to piglets, we also used a WT strain, isolated from infected piglets. K88AC ETEC was kindly provided by Dr Marquardt (University of Manitoba, Winnipeg, MB, Canada). K88WT field isolate was kindly provided by Dr Nick Nation (VPL Laboratories, Edmonton, AB, Canada). To prepare fresh ETEC cultures, ETEC frozen culture was inoculated into $6 \mathrm{ml}$ of brain heart infusion medium (Oxoid Limited, Basingstoke, Hampshire, England, UK) and grown for $24 \mathrm{~h}$ at $37^{\circ} \mathrm{C}$ with shaking, then subcultured for $24 \mathrm{~h}$. The final culture was prepared by $12 \mathrm{~h}$ incubation of a 1:100 dilution of the subculture into brain heart infusion media. Bacteria were diluted in PBS to a final concentration of approximately $1 \times 10^{9}$ colony-forming units $/ \mathrm{ml}$. The presence of K88 fimbriae was confirmed in each culture by a latex agglutination test (Vetway Fimbrex K88; Central Veterinary Laboratory, Addlestone, Surrey, UK) immediately before the surgical procedure.

\section{Epithelial monolayer barrier integrity measurements}

Within $1 \mathrm{~h}$ of death, a small segment from each intestinal loop was removed, transported in ice-cold PBS, stripped of the serosa and mounted in an Ussing chamber. Once mounted, sections were bathed in a bicarbonate Ringer's solution

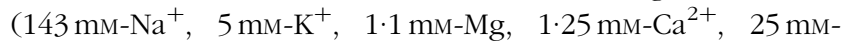
$\mathrm{HCO}_{3}{ }^{-}, 123.7 \mathrm{~mm}_{-} \mathrm{Cl}^{-}, 0.3 \mathrm{~mm}-\mathrm{HPO}_{4}{ }^{-}$and $20 \mathrm{~mm}$-fructose) with $95 \% \mathrm{O}_{2}$ and $5 \% \mathrm{CO}_{2}$ at $37^{\circ} \mathrm{C}, \mathrm{pH} 7 \cdot 4$. Permeability was measured via scintillation counter ( $\beta$-ray scintillation; Beckman Coulter, Fullerton, CA, USA) to determine the flux of $\left[{ }^{3} \mathrm{H}\right]$ mannitol (37 MBq; $1 \mathrm{mCi}$ ) across individual ileal specimens. The spontaneous transepithelial potential difference (PD) and short-circuit current $\left(I_{\mathrm{Sc}}\right)$ were determined for all segments, and tissue conductance $(G)$ was calculated from PD and $I_{\mathrm{sc}}$ according to Ohm's law. At the end of the sampling period, forskolin (10 $\mu \mathrm{l}$; Sigma) was added to the serosal chamber, and the peak change in $I_{\mathrm{sc}}$ was recorded, in order to assess tissue viability.

\section{RNA isolation and PCR analysis of cytokines}

Mucosal samples were ground to a fine powder under liquid $\mathrm{N}_{2}$ using mortar and pestle on dry ice. RNA was extracted using TRIzol reagent (Invitrogen, Burlington, ON, Canada), following the manufacturer's instructions with a slight modification. RNA was precipitated with isopropanol and linear glycogen overnight at $-20^{\circ} \mathrm{C}$. The total RNA concentration of each sample was quantified spectrophotometrically using a NanoDrop ND-1000 Spectrophotometer (NanoDrop Technologies, Wilmington, DE, USA). DNA-free kit (Ambion, Streetsville, ON, Canada) was used to remove any DNA contamination. First-strand complementary DNA synthesis using SuperScript II RT (Invitrogen) on $3 \mu \mathrm{g}$ RNA in a $30 \mu$ l total volume with random primers was done following the manufacturer's guidelines. Real-time PCR was performed on a 7900 HT fast real-time PCR system using $1 \mu \mathrm{l}$ (approximately $100 \mathrm{ng}$ ) complementary DNA, $8 \mu \mathrm{l}$ diethylpyrocarbonate water, $10 \mu \mathrm{l}$ TaqMan Fast Universal PCR Master Mix and $1 \mu \mathrm{l}$ TaqMan Gene Expression Assay. Cycle threshold $\left(C_{\mathrm{t}}\right)$ values were determined using SDS 2.3 software. The gene of interest was normalised to the $C_{\mathrm{t}}$ value of our endogenous reference gene, cyclophilin, using the $\Delta C_{\mathrm{t}}$ method described by Pfaffl $^{(32,33)}$. The primer/probe sequences are listed in Table 2.

\section{Western blotting}

Protein lysates were prepared from intestinal mucosal scrapings by PARIS ${ }^{\mathrm{TM}}$ Protein and RNA Isolation System (Ambion, Austin, TX, USA). The protein concentration of the lysates was determined by bicinchoninic acid assay (Sigma-Aldrich Canada Limited, Oakville, ON, Canada). Equal amounts of protein from each treatment $(20 \mu \mathrm{g})$ were separated by SDS-PAGE on $7.5 \%$ (Zona occludens-1) and $10 \%$ (claudin-1 and occludin) polyacrylamide gels. ECL DualVue ${ }^{\mathrm{TM}}$ Western

Table 2. RT-PCR primers $5^{\prime}-3^{\prime}$

\begin{tabular}{llll}
\hline Genes & Forward primer & TaqMan MGB probes & Reverse primer \\
\hline Cyclophilin & AAT GCT GGC CCC AAC ACA & ACG GTT CCC AGT TTT & TCA GTC TTG GCA GTG CAA ATG \\
IL- 6 & TCTCCACAAGCGCCTTCAG & TCCAGTCGCCTTCTCC & CAGTAGCCATCACCAGAAGCA \\
$T N F-\alpha$ & CCTACTGCACTTCGAGGTTATCG & CCAGCTGGAACTCTT & GGCCAGAGGGTTGATCT \\
IL- $1 \beta$ & AAGGCTCTCCACCTCCTCA & ATGCAGAACACCACTTCT & TTGATCCCTAAGGTCACAGGTATCT \\
IFN- $\gamma$ & GGAAACTGAATGACTTCGAAAAGCT & AAATTCCGGTAGATAATCTG & GGCTTTGCGCTGGATCTG \\
$T$ TGF- $\beta$ & CCTACATCTGGAGCCTAGACACT & CCAGGACCTTGCTGTACTG & GGGTTGTGCTGGTTGTACAGA \\
\hline
\end{tabular}

IFN, interferon; TGF- $\beta$, transforming growth factor- $\beta$. 
blotting markers (Amersham Biosciences, Baie D'Urfe, QC, Canada) were used to monitor protein separation. Proteins were electrophoretically transferred to polyvinylidene difluoride membranes (Amersham Biosciences). Even protein loading and transfer was confirmed by staining with Ponceau S (Sigma-Aldrich Canada Limited). Membranes were blocked for $1 \mathrm{~h}$ at room temperature with TBST $(10 \mathrm{~mm}$-Tris- $\mathrm{HCl}$, $\mathrm{pH} 7 \cdot 4,150 \mathrm{~mm}-\mathrm{NaCl}$, Tween-20 $(1 \mathrm{ml} / \mathrm{l}))$ and powdered milk $(50 \mathrm{~g} / \mathrm{l})$. Primary antibodies to claudin-1 (Santa Cruz Biotechnology, Inc., Santa Cruz, CA, USA) and occludin (Santa Cruz Biotechnology, Inc.) were diluted (1:750 and 1:1500, respectively) in TBST containing powdered milk $(50 \mathrm{~g} / \mathrm{l})$ and incubated with membranes for $1 \mathrm{~h}$ at room temperature. Membranes were incubated with horseradish peroxidase-conjugated anti-rabbit secondary antibody (BD Biosciences, Mississauga, ON, Canada) diluted in TBST containing powdered milk $(50 \mathrm{~g} / \mathrm{l})$ for $1 \mathrm{~h}$ at room temperature. Membranes were developed using an enhanced chemiluminescence (ECL Plus $^{\mathrm{TM}}$ ) detection kit (Amersham Biosciences) and visualised 드 using a Typhoon Trio ${ }^{\text {TM }}$ Imager (GE Healthcare, Baie D'Urfe, QC, Canada). Densitometric values for protein bands were determined using ImageQuant ${ }^{\mathrm{TM}}$ software (GE Healthcare).

\section{Statistical analysis}

All statistical analyses were completed using the SAS statistical package (version 8.1; SAS Institute, Cary, NC, USA). Diet effect was tested using ANOVA, blocked for litter. For epithelial barrier integrity measures and fluid recovery, the effect of diet and loop was determined using a mixed model, with loop comparisons performed by least-squares means, with blocking for piglet litter. Repeated-measures analysis was also performed on Ussing chamber data. For all measurements, a probability of $P<0.05$ was accepted as being statistically significant. Significant differences between groups were identified by least-square means. All results are presented as means with their standard errors. All measured parameters were tested for normal distribution. Values that were not normally distributed were log transformed before statistical analysis.

\section{Results}

\section{Animal weight gain and food intake}

There was no effect of diet on final body weight, weight gain or food intake (Table 3).

\section{Water}

Analysis of fluid recovery data revealed a significant loop effect in which K88AC- and K88WT-inoculated loops were significantly different than the loops that were not inoculated with ETEC $(P<0.0001$; Fig. 1). Gln did not significantly impact fluid secretion in non-inoculated, K88AC- or K88WTinoculated loops $(P=0.069,0.70$ and 0.09 , respectively).
Table 3. Body weight (BW) and food intake of piglets fed the glutamine (GIn) and control (CTL) diets

(Mean values with their standard errors)

\begin{tabular}{lrrrrr}
\hline & \multicolumn{2}{c}{ CTL $(n$ 20) } & & \multicolumn{2}{c}{ Gln $(n$ 20) } \\
\cline { 2 - 3 } \cline { 6 - 7 } & Mean & SEM & & Mean & SEM \\
\hline Final BW $(g)$ & 7740 & 422 & & 8155 & 423 \\
Average weight gain $(g)$ & 1990 & 199 & & 1896 & 248 \\
Food intake (g/d) & 174 & 16 & & 172 & 16 \\
Food intake (g/kg BW) & 25 & 2 & & 22 & 2 \\
\hline
\end{tabular}

\section{Epithelial monolayer barrier integrity measurements}

Within both groups, mannitol flux was significantly higher in intestinal segments inoculated with ETEC (K88AC and K88WT) than non-ETEC segments $(P<0 \cdot 0001$; Fig. 2(A)). Diet did not influence mannitol permeability in either the non-inoculated loops or the ETEC-inoculated loops (Fig. 2(A)).

Electrical measurements of intestinal loop tissue mounted in Ussing chambers revealed that inoculation with K88AC caused an increase in $I_{\mathrm{sc}}$ in control-fed animals (Fig. 2(B)) compared with the CTL loops. Gln feeding resulted in decreased $I_{\mathrm{sc}}$ values in both K88AC- and K88WT-inoculated loops (Fig. 2(B)).

CTL animals had a higher PD in the ETEC-inoculated loops compared with Gln animals, which reached statistical significance in the K88WT-inoculated loops (Fig. 2(C)). All groups responded to forskolin equally at the end of the incubation period, indicating similar viability (change in $I_{\mathrm{sc}}$; data not shown). No differences in conductance $(G)$ were observed between the groups (Fig. 2(D)). These results confirm that both $E$. coli strains produced the expected effects on the gut physiology, therefore only the well-characterised K88AC E. coli strain was used to study the effect of Gln on cytokines and tight-junction proteins.

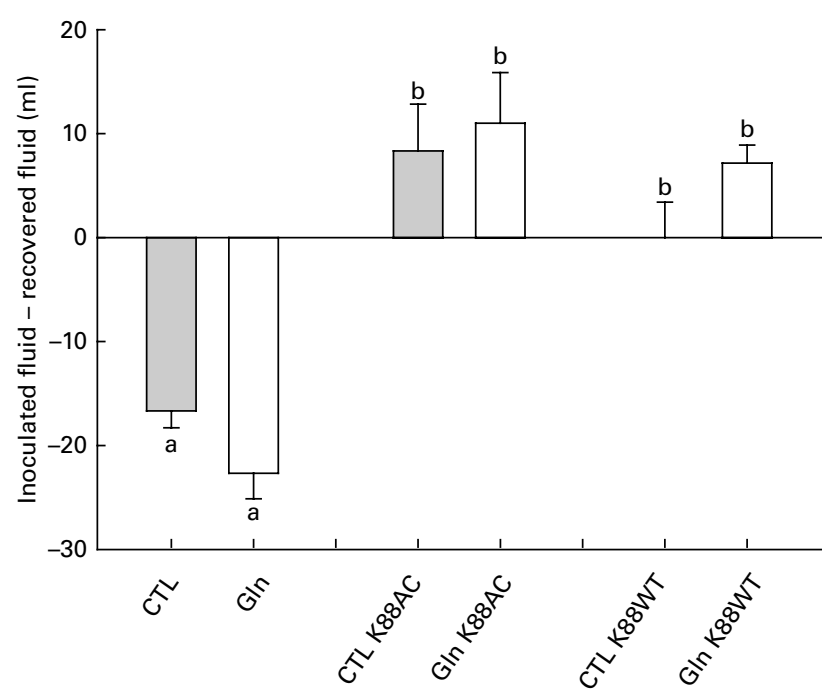

Fig. 1. Fluid recovery from intestinal loops. Fluid volume change in isolated intestinal loops inoculated with or without Escherichia coli from piglets fed the glutamine (GIn) or control (CTL) diets. Values are means of recovered fluid inoculated fluid, with their standard errors represented by vertical bars. ${ }^{\mathrm{a}, \mathrm{b}}$ Mean values with unlike letters were significantly different $(P<0.05)$. 
(A)
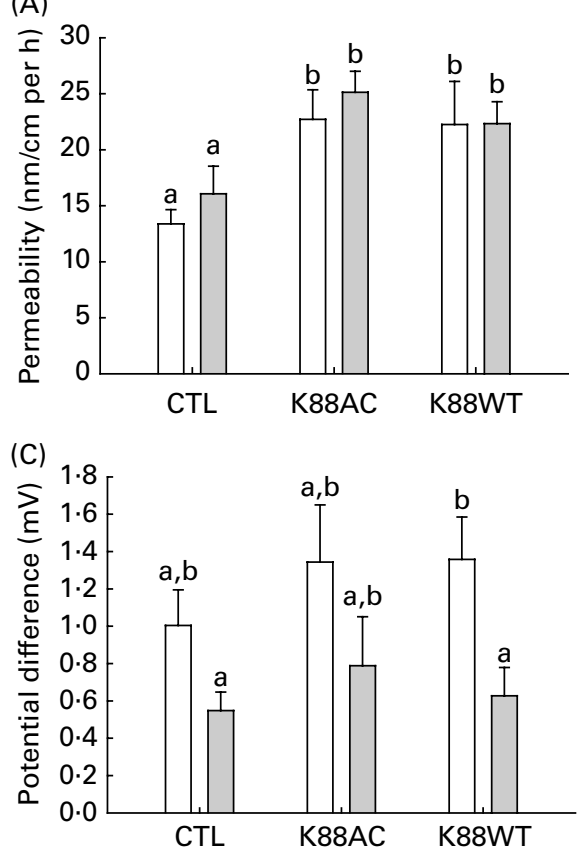

(B)

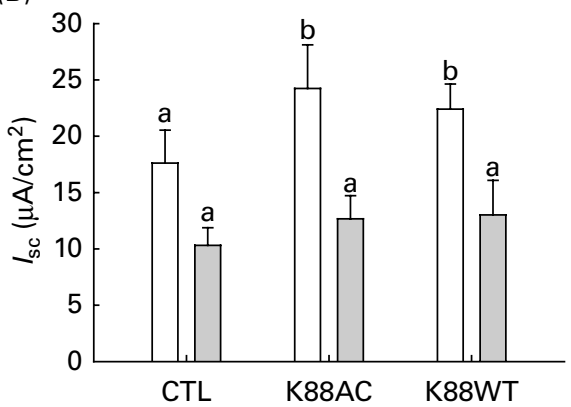

(D)

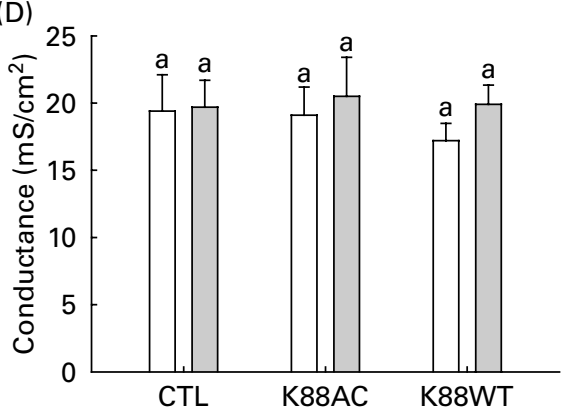

Fig. 2. Ussing chamber analysis. (A) Jejunal mannitol permeability, (B) short-circuit current $\left(I_{\mathrm{sc}}\right)$, (C) potential difference from piglets fed the glutamine (Gln, $\square$, $n 10)$ and control (CTL, $\square)$ diets $(n 10)$ and (D) conductance. Loops were incubated without Escherichia coli (CTL) or with one of the two E. coli strains (K88AC or K88WT). Values are means, with their standard errors represented by vertical bars. ${ }^{\mathrm{a}, \mathrm{b}}$ Mean values with unlike letters were significantly different $(P<0.05)$.

\section{Intestinal cytokine expression}

Neither Gln nor the E. coli (K88AC) challenge significantly influenced the expression of IFN- $\gamma$ in the mucosa of the intestinal loops (Fig. 3). The presence of ETEC stimulated TNF- $\alpha$ and IL-1 $\beta$ expression in both Gln and CTL diets compared with uninfected loops $(P<0 \cdot 01$; Fig. 3$)$. The expression of IL-6 was significantly increased in ETEC-infected loops of control-fed animals compared with uninfected loops, but there was no difference in IL-6 expression in Gln-fed animals between the control and ETEC loops. Transforming growth factor- $\beta$ and IL-10 were significantly higher in the ETECchallenged intestinal loops compared with the control loop in control-fed animals, but in Gln-fed animals $(P<0.05)$, no differences were observed in these cytokines between the ETEC-infected and control loops (Fig. 3). Gln supplementation did not significantly alter the expression of any measured cytokine in ETEC-infected loops compared with the CTL diet.

\section{Effects on tight-junction proteins}

There was a significant decrease in the levels of occludin and claudin-1 in the mucosa from $E$. coli-challenged loops $(P<0.002$; Fig. 4). There was no significant effect of diet on the expression of claudin- 1 in the mucosa. After the ETEC challenge, there was a trend $(P=0.06)$ towards a higher expression of occludin in Gln-fed piglets, compared with CTL piglets.

\section{Discussion}

In the present study, we investigated the impact of feeding Gln on immune and intestinal barrier function in a piglet model of weaning-associated ETEC infection. We found that piglets fed Gln before E. coli infection had decreased intestinal PD and $I_{\mathrm{sc}}$ compared with control-fed animals. We also observed a significantly increased expression in

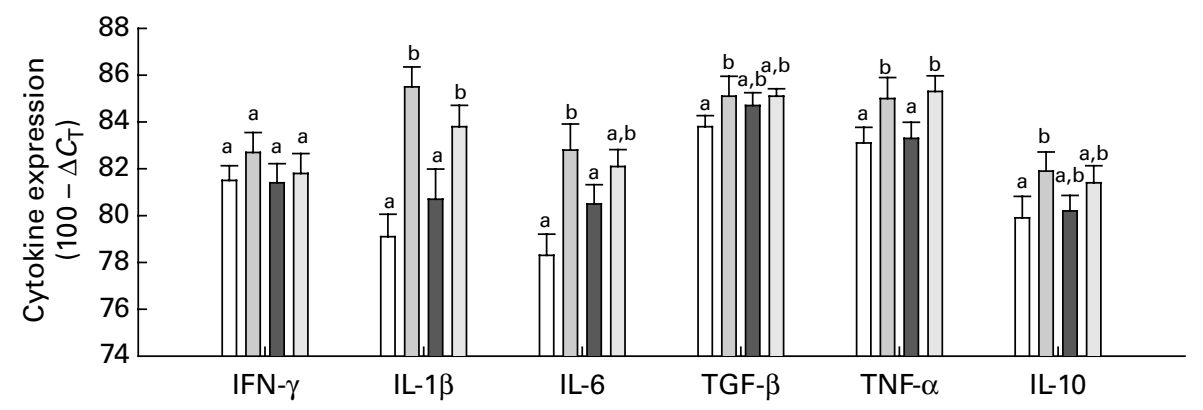

Fig. 3. Intestinal cytokine expression. Values are means with their standard errors represented by vertical bars (gene-specific cytokine RNA expressed as $100-\Delta C_{\mathrm{T}}$ (eight per group)). $\Delta C_{\mathrm{T}}$ was calculated by correcting to the level of $18 \mathrm{~S}$ (which was not significantly affected by diet or Escherichia coli). ${ }^{\text {, b }}$ Mean values with unlike letters were significantly different as determined by a repeated-measures ANOVA and least-square means $(P \leq 0.05)$. IFN, interferon; TGF- $\beta$, transforming growth factor- $\beta$; $\square$, control (CTL); $\square$, CTL + E. coli; $\square$, GIn; $\square$, Gln + E. coli. 

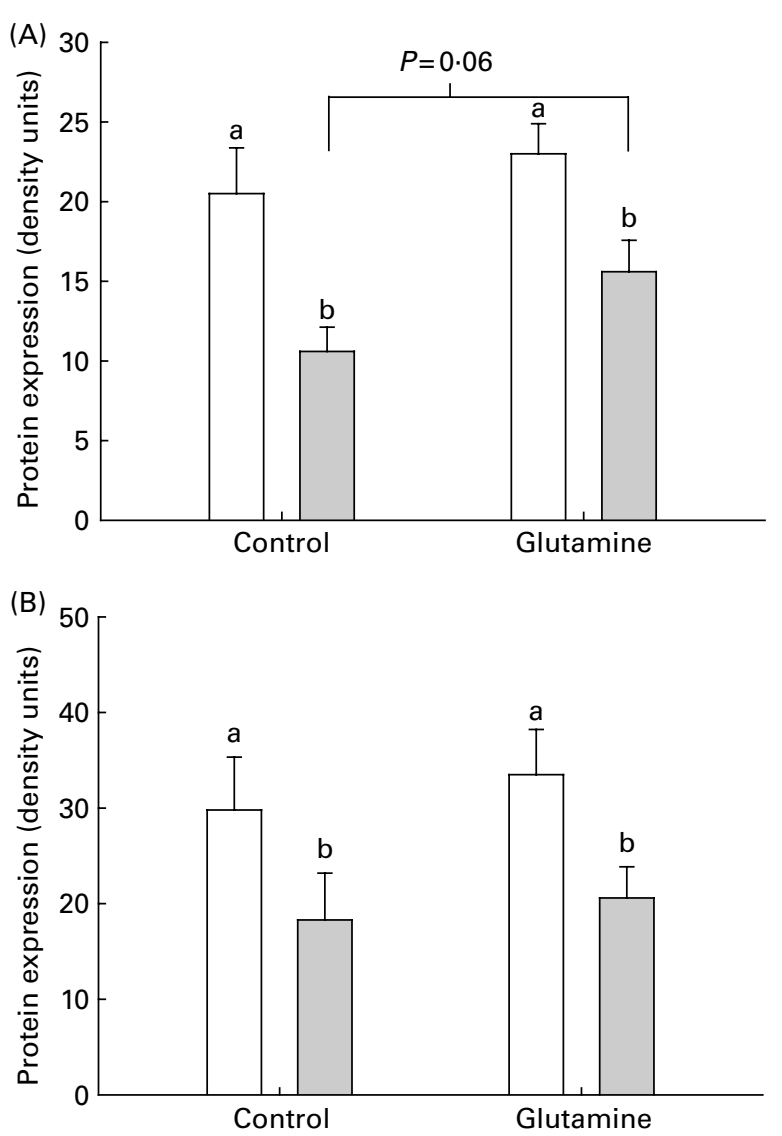

Fig. 4. (A) Occludin and (B) claudin-2 and protein expression in intestinal mucosa from piglets fed the glutamine (Gln) or control ( $\square$ ) diets. ${ }^{a, b}$ Mean values were significantly different in the levels of occludin and claudin-1 in the mucosa from Escherichia coli $(\square)$-challenged loops $(P<0.002)$. There was no significant effect of Gln on the expression of claudin-1 in the mucosa.

mucosal cytokine mRNA expression (IL-6, transforming growth factor- $\beta$ and IL-10) in response to ETEC infection in control-fed animals, but not in Gln-fed animals. Fluid secretion and tight-junction protein expression were both negatively altered by $E$. coli infection in both control-fed and Gln-fed piglets.

FI was slightly lower in the present study than that in a similar study of Gln supplementation (0-1\%) of $21 \mathrm{~d}$ weaned piglets $^{(26)}$. In the present study, average daily FI was approximately $174 \mathrm{~g} / \mathrm{d}$ over the $14 \mathrm{~d}$ experimental period, whereas the above-mentioned study reports FI in two periods: the first week post-weaning (about $140 \mathrm{~g} / \mathrm{d}$ ) and the second week post-weaning (about $350 \mathrm{~g} / \mathrm{d}$ ). This makes the direct comparison difficult; however, it does appear that there was probably a lower FI in the present study. Given that the control-fed and Gln-fed piglets consumed the same amount of feed in the present study, it seems unlikely that it is due to Gln supplementation, which was significantly higher in the present study ( $4.38 v .1 \%)$. This difference may be attributable to the breed selected - the present study was performed using Dutch Landrace cross piglets, whereas Wu et al. ${ }^{(26)}$ utilised Yorkshire $\times$ Landrace sows and Duroc $\times$ Hampshire boars.

ETEC causes diarrhoea by adhering to intestinal epithelial cells via pili or fimbriae and subsequently producing enterotoxins (heat-stable and heat-labile) (reviewed in Gyles ${ }^{(34)}$ ), which lead to a decrease in the absorption of electrolytes by the villus cells and an increase in $\mathrm{Cl}^{-}$secretion by the crypt cells. This rapid increase in the rate of secretion of electrolytes and water from the intestine leads to diarrhoea. The immune system becomes activated by the presence of ETEC on intestinal cells, and inflammation ensues ${ }^{(35,36)}$. This process was in agreement with the present study, as shown by the higher fluid absorption in non-ETEC-exposed loops (demonstrated by the lower recovery of liquid from these loops). We found that dietary Gln supplementation before an E. coli challenge did not prevent the increase in fluid secretion. In contrast, Silva et $a l{ }^{(37)}$ used a rabbit model (cholera toxin-infected intestinal loop sections) and found that Gln-supplemented oral rehydration solution was capable of reducing water secretion. Similarly, PG-induced secretion has been reported to be reduced in the presence of Gln infusion in human subjects ${ }^{(38)}$. These discrepancies may be attributable to the use of Gln after infection is initiated, whereas in the present study, Gln supplementation occurred as a dietary pre-treatment to $E$. coli infection, rather than an intestinal infusion at the time of induction of secretion. Furthermore, since the precise ionic composition of the luminal contents is unknown in the present study, the aetiology of altered fluid secretion is unknown.

We also observed solute movement across the paracellular pathway, via measurement of the unidirectional serosalto-mucosal flux of mannitol. A significantly higher mannitol permeability was found in loops inoculated with ETEC (K88AC and K88WT), indicating an increased intestinal permeability in the presence of ETEC. An increase in permeability due to the presence of pathogens has previously been reported in studies of in vivo infection by transmissible gastroenteritis virus ${ }^{(39)}$ and rotavirus ${ }^{(40)}$ in piglets and rats, respectively. Reduced enterotoxin-induced enterocyte death ${ }^{(41)}$ and decreased bacterial translocation ${ }^{(42)}$ have also been reported following oral administration of Gln. In the present study, there was no significant effect of Gln supplementation on mannitol permeability before or after an intestinal $E$. coli challenge. Dietary Gln has been shown in numerous studies to exert trophic effects on the intestinal epithelium, leading to increased villus height, improved mucosal integrity and cell proliferation ${ }^{(23,43,44)}$. Since an increase in surface area would also increase mannitol permeability, diet-induced changes could potentially be masked if enterocyte proliferation and surface area were increased.

In the present study, jejunal intestinal sections did not demonstrate a significant change in $G$ in response to ETEC in control-fed or Gln-fed piglets. The forskolin response (change in $I_{\mathrm{sc}}$ ) was significantly higher in the intestinal loops from Gln-fed piglets infected with both K88AC and K88WT with ETEC exposure compared with the CTL-fed piglets. Similarly, PD was higher in K88WT ETEC-infected loops from Gln-fed animals compared with CTL-fed animals. Tissue $I_{\mathrm{sc}}$ in Ussing chambers is a measure of the net movement of several actively transported ions, which significantly increases following the addition of heat-stable enterotoxin to rabbit distal ileal sections ${ }^{(45)}$. PD is also related to ion 
movement but measures changes in the electrochemical gradient across the intestinal epithelium that is generated by electrogenic ion pumps in epithelial cell membranes, mainly the Na-K-ATPase ${ }^{(46)}$. Although the movement of individual ions was not measured in the present study, the higher $I_{\mathrm{Sc}}$ and PD values in ETEC-infected loops of CTL-fed piglets compared with Gln-fed piglets are suggestive of an increased $\mathrm{Cl}^{-}$secretion caused by ETEC. It is possible that enterocytes of Gln-fed piglets were not influenced to the same extent by the presence of ETEC, either by being less responsive to secreted enterotoxins or because ETEC was not able to bind and release enterotoxins to the same magnitude. The decrease in intestinal cytokine production that we observed could similarly be attributed to reduced binding and enterotoxin production of ETEC.

Alternately, Gln may have had a direct effect on intestinal cytokine production. Feeding Gln has been shown to reduce the production of the pro-inflammatory cytokines IL- 6 and IL-8, in response to IL-1 $\beta$ stimulation in human intestinal mucosa ${ }^{(47)}$. Consistent with the present study, Gln supplementation has also been shown to reduce plasma inflammatory cytokine concentrations (TNF- $\alpha$ and IL- 6 ) in response to $E$. coli lipopolysaccharide-induced shock, via induction of HSP70 expression ${ }^{(48)}$. In that study, Gln also enhanced the production of the regulatory cytokine, IL- $10^{(45)}$. In the present study, there was an increase in IL-10 in the intestines from Gln-fed piglets compared with control-fed piglets.

Although it has been demonstrated that feeding Gln can reduce the risk of enteric infections in piglets ${ }^{(14)}$ and infants $^{(12)}$, the relative contribution of dietary Gln to immune development and health has not been clearly established. In a previous study by our group, healthy piglets feeding a weaning diet supplemented with Gln exhibited enhanced immune function, including increased proliferation of peripheral blood mononuclear cells and mesenteric lymph node cells after an antigen challenge and prevention of an increase in antigen-naive $\mathrm{CD}^{+}$cells $^{(6)}$. To prevent post-weaning ETEC-induced diarrhoea, an activated mucosal immunity system is required ${ }^{(49)}$. The process by which animals meet the immediate response to infection is influenced by inflammatory cytokines produced primarily by macrophages and professional antigen-presenting cells ${ }^{(50)}$. It is possible that this activated mucosal immunity in turn alters tight-junction protein expression, as pro-inflammatory cytokines are known to induce endocytosis of tight-junction proteins and subsequently cause increased permeability ${ }^{(35)}$.

In summary, the results of the present study suggest that Gln supplementation during the weaning period is useful in reducing early steps in weaning-related gastrointestinal infections by suppressing the inflammatory and regulatory cytokine response in the gut and decreasing damage to tight junction proteins and intestinal electrolyte movement.

\section{Acknowledgements}

The present study was supported by the Canadian Institutes of Health Research and Alberta Pork with the Alberta Agriculture Research Institute. The authors would like to acknowledge the technical assistance provided by Susan Goruk, Michelle Tavernini and Grace Chen, and the excellent animal care provided by the outstanding technical assistance of the animal technicians Brenda Tchir and Charlene Gorsak at the University of Alberta Metabolic Unit. J. B. E. participated in the data analysis, and drafted and edited the manuscript. G. K. M. designed the PCR probes, conducted the cytokine analysis and participated in the data analysis. I. R. J. carried out the studies and conducted the preliminary data analysis. K. L. M. participated in the study design and carried out the Ussing chamber analyses. C. J. F. conceived the study, participated in its design, coordination and supervision. There are no financial or personal conflicts of interest to report.

\section{References}

1. The United Nations Children's Fund (UNICEF)/World Health Organization (WHO) (2010) Diarrhoea: Why Children are Still Dying and What Can be Done About it. New York/ Geneva: UNICEF/WHO.

2. Nweze EI (2010) Aetiology of diarrhoea and virulence properties of diarrhoeagenic Escherichia coli among patients and healthy subjects in southeast Nigeria. J Health Popul Nutr 28, 245-252.

3. Nabuurs MJ (1998) Weaning piglets as a model for studying pathophysiology of diarrhea. Vet $Q \mathbf{2 0}$, Suppl. 3, S42-S45.

4. Juul-Madsen HR, Jensen KH, Nielsen J, et al. (2009) Ontogeny and characterization of blood leukocyte subsets and serum proteins in piglets before and after weaning. Vet Immunol Immunopathol 133, 95-108.

5. Bianchi AT, Zwart RJ, Jeurissen SH, et al. (1992) Development of the B- and T-cell compartments in porcine lymphoid organs from birth to adult life: an immunohistological approach. Vet Immunol Immunopathol 33, 201-221.

6. Johnson IR, Ball RO, Baracos VE, et al. (2006) Glutamine supplementation influences immune development in the newly weaned piglet. Dev Comp Immunol 30, 1191-1202.

7. Solano-Aguilar GI, Vengroski KG, Beshah E, et al. (2001) Characterization of lymphocyte subsets from mucosal tissues in neonatal swine. Dev Comp Immunol 25, 245-263.

8. Vega-Lopez MA, Bailey M, Telemo E, et al. (1995) Effect of early weaning on the development of immune cells in the pig small intestine. Vet Immunol Immunopathol $\mathbf{4 4}$, 319-327.

9. Bailey M, Miller BG, Telemo E, et al. (1993) Specific immunological unresponsiveness following active primary responses to proteins in the weaning diet of piglets. Int Arch Allergy Immunol 101, 266-271.

10. Darwich L, Segales J, Domingo M, et al. (2002) Changes in CD4(+), CD8(+), CD4(+) CD8(+), and immunoglobulin M-positive peripheral blood mononuclear cells of postweaning multisystemic wasting syndrome-affected pigs and age-matched uninfected wasted and healthy pigs correlate with lesions and porcine circovirus type 2 load in lymphoid tissues. Clin Diagn Lab Immunol 9, 236-242.

11. Forchielli ML \& Walker WA (2005) The effect of protective nutrients on mucosal defense in the immature intestine. Acta Paediatr Suppl 94, 74-83.

12. van den Berg A, van Elburg RM, Westerbeek EA, et al. (2005) Glutamine-enriched enteral nutrition in very-lowbirth-weight infants and effects on feeding tolerance and infectious morbidity: a randomized controlled trial. $\mathrm{Am} \mathrm{J}$ Clin Nutr 81, 1397-1404. 
13. Chamorro S, de Blas C, Grant G, et al. (2009) Effect of dietary supplementation with glutamine and a combination of glutamine-arginine on intestinal health in 25 -d-old weaned rabbits. J Anim Sci 88, 170-180.

14. Yi GF, Carroll JA, Allee GL, et al. (2005) Effect of glutamine and spray-dried plasma on growth performance, small intestinal morphology, and immune responses of Escherichia coli $\mathrm{K} 88+$-challenged weaned pigs. J Anim Sci $\mathbf{8 3}$, 634-643.

15. DeMarco VG, Li N, Thomas J, et al. (2003) Glutamine and barrier function in cultured Caco-2 epithelial cell monolayers. J Nutr 133, 2176-2179.

16. Scheppach W, Dusel G, Kuhn T, et al. (1996) Effect of L-glutamine and $n$-butyrate on the restitution of rat colonic mucosa after acid induced injury. Gut 38, 878-885.

17. Evans ME, Jones DP \& Ziegler TR (2005) Glutamine inhibits cytokine-induced apoptosis in human colonic epithelial cells via the pyrimidine pathway. Am J Physiol Gastrointest Liver Physiol 289, G388-G396.

18. Wu GY, Field CJ \& Marliss EB (1991) Glutamine and glucose metabolism in rat splenocytes and mesenteric lymph node lymphocytes. Am J Physiol 260, E141-E147.

19. Wu GY, Field CJ \& Marliss EB (1991) Glucose and glutamine metabolism in rat macrophages: enhanced glycolysis and unaltered glutaminolysis in spontaneously diabetic BB rats. Biochim Biophys Acta 1115, 166-173.

20. Newsholme P (2001) Why is L-glutamine metabolism important to cells of the immune system in health, postinjury, surgery or infection? J Nutr 131, 2515S-2522S.

21. Ogle CK, Ogle JD, Mao J-X, et al. (1994) Effect of glutamine on phagocytosis and bacterial killing by normal and pediatric burn patient neutrophils. JPEN J Parenter Enteral Nutr 18, 128-133.

22. Dugan ME \& McBurney MI (1995) Luminal glutamine perfusion alters endotoxin-related changes in ileal permeability of the piglet. JPEN J Parenter Enteral Nutr 19, 83-87.

23. Wang J, Chen L, Li P, et al. (2008) Gene expression is altered in piglet small intestine by weaning and dietary glutamine supplementation. J Nutr 138, 1025-1032.

24. Field CJ, Thomson CA, Van Aerde JE, et al. (2000) Lower proportion of CD45R0 + cells and deficient interleukin-10 production by formula-fed infants, compared with humanfed, is corrected with supplementation of long-chain polyunsaturated fatty acids. I Pediatr Gastroenterol Nutr 31 , 291-299.

25. Klimberg VS, Salloum RM, Kasper M, et al. (1990) Oral glutamine accelerates healing of the small intestine and improves outcome after whole abdominal radiation. Arch Surg 125, 1040-1045.

26. Wu G, Meier SA \& Knabe DA (1996) Dietary glutamine supplementation prevents jejunal atrophy in weaned pigs. J Nutr 126, 2578-2584.

27. Dhaliwal R \& Heyland DK (2005) Nutrition and infection in the intensive care unit: what does the evidence show? Curr Opin Crit Care 11, 461-467.

28. Sarmiento JI, Casey TA \& Moon HW (1988) Postweaning diarrhea in swine: experimental model of enterotoxigenic Escherichia coli infection. Am J Vet Res 49, 1154-1159.

29. Wu G (2009) Amino acids: metabolism, functions, and nutrition. Amino Acids 37, 1-17.

30. Field CJ, Johnson I \& Pratt VC (2000) Glutamine and arginine: immunonutrients for improved health. Med Sci Sports Exerc 32, S377-S388.

31. Field M (1976) Regulation of active ion transport in the small intestine. Ciba Found Symp 109-127.
32. Pfaffl MW (2004) Quantification strategies in real-time PCR. In A-Z of Quantitative PCR, pp. 89-120 [SA Bustin, editor] LaJolla, CA: International University Line.

33. Pfaffl MW (2001) A new mathematical model for relative quantification in real-time RT-PCR. Nucleic Acids Res 29, e45.

34. Gyles CL (1992) Escherichia coli cytotoxins and enterotoxins. Can J Microbiol 38, 734-746.

35. Al-Sadi R, Boivin M \& Ma T (2009) Mechanism of cytokine modulation of epithelial tight junction barrier. Front Biosci 14, 2765-2778.

36. Duchmann R, Neurath M, Marker-Hermann E, et al. (1997) Immune responses towards intestinal bacteria - current concepts and future perspectives. $Z$ Gastroenterol 35 337-346.

37. Silva AC, Santos-Neto MS, Soares AM, et al. (1998) Efficacy of a glutamine-based oral rehydration solution on the electrolyte and water absorption in a rabbit model of secretory diarrhea induced by cholera toxin. I Pediatr Gastroenterol Nutr 26, 513-519.

38. Coeffier M, Hecketsweiler B, Hecketsweiler P, et al. (2005) Effect of glutamine on water and sodium absorption in human jejunum at baseline and during PGE1-induced secretion. J Appl Physiol 98, 2163-2168.

39. Keljo DJ, Butler DG \& Hamilton JR (1985) Altered jejunal permeability to macromolecules during viral enteritis in the piglet. Gastroenterology 88, 998-1004.

40. Isolauri E, Kaila M, Arvola T, et al. (1993) Diet during rotavirus enteritis affects jejunal permeability to macromolecules in suckling rats. Pediatr Res 33, 548-553.

41. Haynes TE, Li P, Li X, et al. (2009) L-Glutamine or L-alanylL-glutamine prevents oxidant- or endotoxin-induced death of neonatal enterocytes. Amino Acids 37, 131-142.

42. Gianotti L, Alexander JW, Gennari R, et al. (1995) Oral glutamine decreases bacterial translocation and improves survival in experimental gut-origin sepsis. JPEN J Parenter Enteral Nutr 19, 69-74.

43. Baskerville A, Hambleton P \& Benbough JE (1980) Pathological features of glutaminase toxicity. Br J Exp Pathol 61, 132-138.

44. Domeneghini C, Di GA, Bosi G, et al. (2006) Can nutraceuticals affect the structure of intestinal mucosa? Qualitative and quantitative microanatomy in L-glutamine dietsupplemented weaning piglets. Vet Res Commun 30, $331-342$.

45. Guandalini S, Rao MC, Smith PL, et al. (1982) cGMP modulation of ileal ion transport: in vitro effects of Escherichia coli heat-stable enterotoxin. Am J Physiol 243, G36-G41.

46. Armstrong CP, Taylor TV \& Torrence HB (1987) Ionic flux and mucosal ultrastructure in the rat bile-pancreatic duct. Effect of bile salt perfusion on duct integrity. Dig Dis Sci 32, $861-871$.

47. Coeffier M, Marion R, Ducrotte P, et al. (2003) Modulating effect of glutamine on IL-1beta-induced cytokine production by human gut. Clin Nutr 22, 407-413.

48. Jing L, Wu Q \& Wang F (2007) Glutamine induces heat-shock protein and protects against Escherichia coli lipopolysaccharide-induced vascular hyporeactivity in rats. Crit Care 11, R34.

49. Snoeck V, Huyghebaert N, Cox E, et al. (2003) Enteric-coated pellets of F4 fimbriae for oral vaccination of suckling piglets against enterotoxigenic Escherichia coli infections. Vet Immunol Immunopathol 96, 219-227.

50. Murtaugh MP \& Foss DL (2002) Inflammatory cytokines and antigen presenting cell activation. Vet Immunol Immunopathol 87, 109-121. 